\title{
Effect of elicitation on polyphenol and carotenoid metabolism in butterhead lettuce
}

(Lactuca sativa var. capitata)

Jesus Omar Moreno-Escamilla ${ }^{\dagger}$, Fatima Estefania Jimenez-Hernandez ${ }^{\dagger}$, Emilio Alvarez-

Parrilla ${ }^{\dagger}$, Laura A. de la Rosa ${ }^{\dagger}$, Nina del Rocio Martinez-Ruiz ${ }^{\dagger}$, Raquel GonzálezFernández ${ }^{\dagger}$, Ernesto Orozco-Lucero, Gustavo A. González-Aguilar*, Jorge A. GarcíaFajardo\& and Joaquin Rodrigo-García $^{\S *}$

†Departamento de Ciencias Químico-Biológicas, Instituto de Ciencias Biomédicas, Universidad Autónoma de Ciudad Juárez, Anillo envolvente del PRONAF y Estocolmo s/n, Ciudad Juárez, Chihuahua, 32310, México

†Coordinación de Tecnología de Alimentos de Origen Vegetal, Centro de Investigación en Alimentación y Desarrollo, Carretera a la Victoria Km 0.6, Hermosillo, Sonora, 8300, México

${ }^{\&}$ Centro de Investigación y Asistencia en Tecnología y Diseño del Estado de Jalisco, A.C. Vía de la Innovación 404. Autopista Mty-Aeropuerto Km 10, Parque PIIT. Apodaca, Nuevo León, 66629, México

$\S$ Departamento de Ciencias de la Salud, Instituto de Ciencias Biomédicas, Universidad Autónoma de Ciudad Juárez, Anillo envolvente del PRONAF y Estocolmo s/n, Ciudad Juárez, Chihuahua, 32310, México

* corresponding author: jogarcia@uacj.mx, Ph +52 (656) 688-1800 ext 1491 
Figure 1s, supplementary data

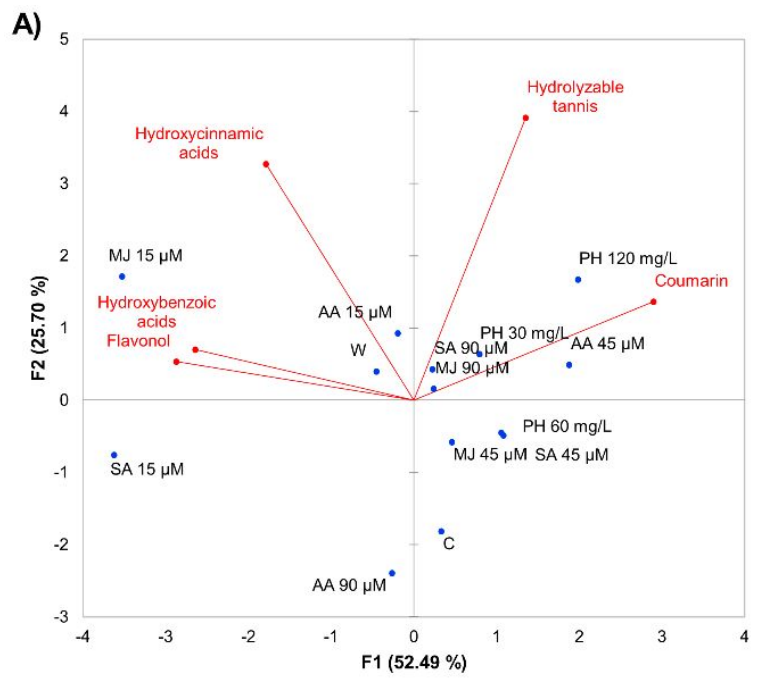

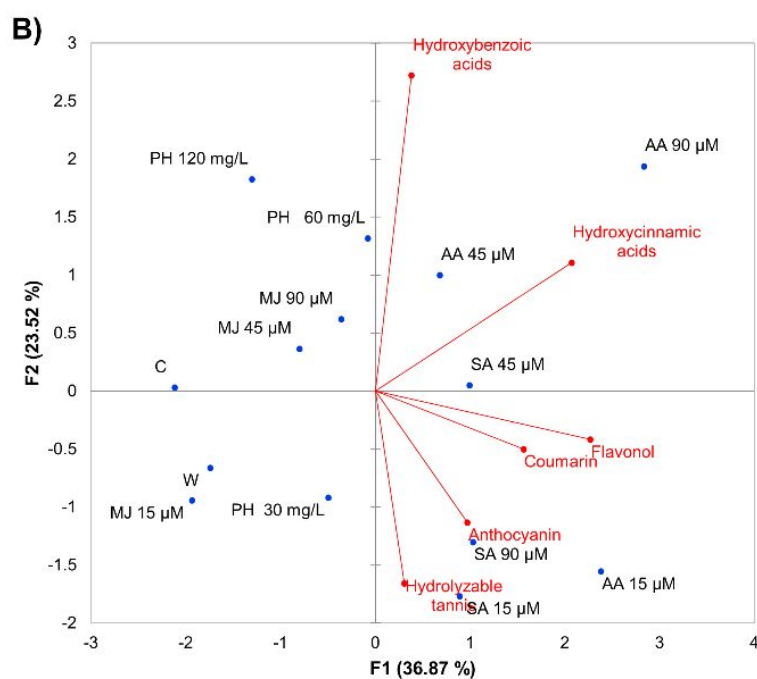

Figure 1s. PCA analysis of effect of elicitors in polyphenol profile in green $(A)$ and red $(B)$ butterhead lettuce. AA, arachidonic acid; SA, salicylic acid; MJ, methyl jasmonate; HP, Harpin protein 
Table 1s, supplementary data

Table 1s. Secondary metabolite synthesis enzyme genes and housekeeping gene used for RT-PCR analysis in butterhead lettuce after elicitation

\begin{tabular}{lccc}
\hline Gene & Sequence 5'-3' & $\begin{array}{c}\text { Tm } \\
\left({ }^{\circ} \mathbf{C}\right)\end{array}$ & $\begin{array}{c}\text { Product } \\
\text { size (bp) }\end{array}$ \\
\hline PAL & agatggttgcggagttcaga/caccgccttgcttagttctc & 56.0 & 249 \\
LBC & tggcccatagaaaggagacg/caggcgagatgacaagaagc & 57.7 & 150 \\
UFGT & gaggaggaaagtggggtgaa/cagctacaacttctggtggc & 58.9 & 238 \\
PP2A-1 & ctgttgcatggaggcctt/caaacgtgtaaccagcacca & 50.0 & 170 \\
\hline
\end{tabular}

PAL, Phenylalanine ammonia lyase; LBC, Lycopene beta cyclase; UFGT, UDP-glucose flavonoid 3-O-glucosyltransferase.; PP2A-1, Serine/threonine-protein phosphatase 